\title{
Content of carotenoids in roots of seventeen cultivars of Daucus carota L.
}

\author{
Aleksandra Mech-Nowak ${ }^{1}$, Adam Świderski ${ }^{1}$, Michał Kruczek¹, Irena Łuczak² and \\ Anna Kostecka-Gugała ${ }^{1}$
}

1Department of Biochemistry, University of Agriculture, Kraków, Poland; 2Department of Plant Protection, University of Agriculture, Kraków, Poland

\begin{abstract}
The aim of this study was to compare the content of carotenoids in seventeen cultivars of carrots grown in Poland. Conventional orange cultivars with rarely grown were compared: white, yellow and purple with yellow core cultivars. To determine the content of carotenoids, extracts from lyophilized carrot roots were prepared and analyzed by spectrophotometric as well as HPLC methods with DAD detector. The highest content of carotenoids was found in cultivars: 'Korund $F_{1}$ ' (48 mg/100g of fresh weight) and 'Salsa $F_{1}$ ' (36 $\mathrm{mg} / 100 \mathrm{~g}$ of fresh weight). The antioxidant properties of selected cultivars were compared using the DPPH method.
\end{abstract}

Key words: carotenoid, carrot, antioxidant activity

Received: 14 October, 2011; accepted: 01 March, 2012; available on-line: 17 March, 2012

\section{INTRODUCTION}

Carrots are an important source of carotenoids in daily diet (Arscott \& Tanumihardjo, 2010). They mainly provide not only $\beta$-caroten which is needed as provitamin A (Rao \& Rao, 2007; Grune et al., 2010), but also other carotenids for example lutein which protects against agerelated macular degeneration and cataract (Mozaffarieh et al., 2003; El-Agamey et al., 2004). Carotenoids present in Daucus carota L., are also antioxidants that are able to reduce the risk of chronic diseases (cardiovascular diseases, cancer ect.) (Krinsky \& Yeum, 2003; Paolini et al., 2003; Stahl \& Sies, 2003). In Poland, the carrot is grown on a large scale (813 000 tons in 2009) and has great economic importance (GUS 2009). New cultivars introduced into crops are not only different in shapes and colors, but also in the content of bioactive and important for health compounds including carotenoids. Several studies on carotenoids content of carrots have been reported (Surles et al., 2004; Grassmann et al., 2007; Sun et al., 2009) however, none of them includes differences in cultivars. Identifying the Daucus carota L. cultivars with the highest carotenoids content in roots will make it possible to recommend them for cultivation, especially for farms specializing in production of preserves with high carotenoids content and contribute to further selection of new cultivars in horticultural breeding.

\section{MATERIALS AND METHODS}

Seventeen selected cultivars of carrots were grown on plots at the Experimental Station of Agricultural Uni- versity in Mydlniki. After harvesting, samples of carrot roots were immediately frozen at $-20^{\circ} \mathrm{C}$. Each $10 \mathrm{~g}$ sample was freeze-dried. After lyophilisation, the carrots were extracted using $\mathrm{n}$-hexane/ethanol $96 \%$ (1:1, v/v), until complete exhaustion of colour (Andersson et al., 2009). The whole extract was kept at $-20^{\circ} \mathrm{C}$ and used for HPLC and spectrophotometric analyses within 72 h. The HPLC system consisted of a Shimadzu LC-20 AD model with a LiChrospher RP-18, $250 \mathrm{~mm}$ column. The mobile phase comprised $1 \%$ water in methanol (A), methanol (B), 10\% n-hexane with acetonitrile (C) with gradient method at a flow rate of $2.0 \mathrm{ml} / \mathrm{min}$. Detection was carried out using a DAD (diode array detector). Quantification of total carotenoids was performed on UV/Vis Spectrophotometer JASCO V-530. To determine the antioxidant capacity of carrots extract DPPH (Wang et al., 2010) method was used. Statistical analysis were performed with Statistica (version 9). Analysis of variance (ANOVA) was used to investigate differences among carotenoids content of various cultivars. To find out relation between carotenoids content and antioxidant capacity test of correlation was performed.

\section{RESULTS AND DISCUSSION}

Because of the high carotenoids content, carrot is main vegetable consumed in Europe. In this research seventeen new carrot cultivars were compared in consideration of their total carotenoids content. Among all examined cultivars the highest total carotenoids content (all types of carotenoids) were found in orange carrots (14 cultivars). The studies showed that the most valuable cultivars in terms of their carotenoids content, are 'Korund $\mathrm{F}_{1}$ ', 'Salsa $\mathrm{F}_{1}$ ', 'Afro $\mathrm{F}_{1}$ ', 'Kazan $\mathrm{F}_{1}$ ', 'Polka $\mathrm{F}_{1}$ ', 'Kongo $\mathrm{F}_{1}$ ', 'Niland $\mathrm{F}_{1}$ ' (Fig. 1). The yellow, white and purple cultivars as we expected contained much less carotenoids. Especially white ('White Satin') and yellow ('Yellowstone') cultivars had small amounts of carotenoids: 'White Satin' — $0.54 \mathrm{mg} / 100 \mathrm{~g}$ fresh weight, 'Yellowstone' - $2.75 \mathrm{mg} / 100 \mathrm{~g}$ fresh weight (Table 1). The purple roots with yellow core ('Deep Purple') had more carotenoids (3.46 mg/100 g fresh weight) but still much less than traditional orange cultivars. Grassmann et al. (2007) found higher values of total carotenoids for

e-mail: aleksandra.mech.nowak@gmail.com * Presented at the 16th International Symposium on Carotenoids, 17-22 July, 2011, Kraków, Poland

Abbreviations: DPPH, diphenylpicrylhydrazyl; HPLC, high performance liquid chromatography. 


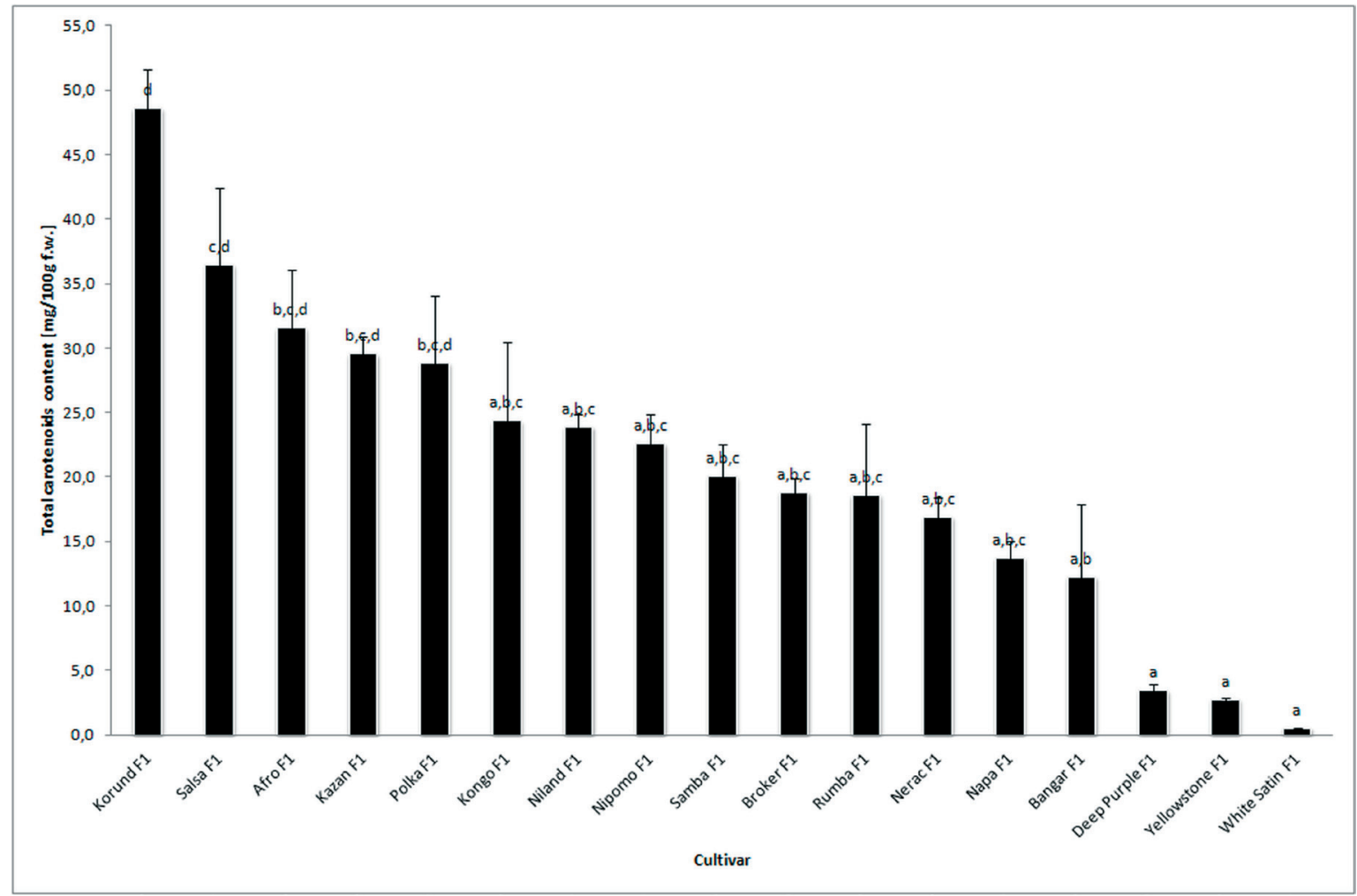

Figure 1. Content of total carotnenoids in seventeen different cultivars of carrot.

Data with significant differences are labeled with different letters.

purple cultivar. This difference is probably due to the fact that Grassmann studied the purple cultivar with orange core, in turn, the object of our study was also a

Table 1. Content of $\beta$-caroten, total carotenes and xanthophylls in seventeen cultivars of Daucus carota L.

\begin{tabular}{|c|c|c|c|}
\hline $\begin{array}{l}\text { Total content } \\
\text { [mg/100 g f.w.*] } \\
\text { Cultivar }\end{array}$ & $\beta$-caroten & Carotenes & Xanthophylls \\
\hline Korund $\mathrm{F}_{1}$ & $13.0 \pm 7.31^{c}$ & $19.7 \pm 1.27^{b}$ & $1.8 \pm 0.25^{\mathrm{fg}, \mathrm{h}}$ \\
\hline Salsa $F_{1}$ & $13.9 \pm 4.41^{a, b}$ & $22.8 \pm 7.29$ b & $1.3 \pm 0.32^{\mathrm{b}, \mathrm{c}, \mathrm{d}}$ \\
\hline Afro $F_{1}$ & $16.7 \pm 7.2^{\mathrm{b}, \mathrm{c}}$ & $27.4 \pm 7.31^{b}$ & $1.1 \pm 0.06^{b, c}$ \\
\hline Kazan $\mathrm{F}_{1}$ & $17.1 \pm 3.7^{b, c}$ & $28.0 \pm 6.42^{b}$ & $1.5 \pm 0.05_{c, d, d, f f}$ \\
\hline Polka $F_{1}$ & $11.9 \pm 2,13^{a, b}$ & $24.5 \pm 6.19 b$ & $1.8 \pm 0.18^{e, f, g}$ \\
\hline Kongo $F_{1}$ & $13.7 \pm 0.83^{\mathrm{a}, \mathrm{b}}$ & $20.2 \pm 0.71^{b}$ & $2.3 \pm 0.11^{i}$ \\
\hline Niland $F_{1}$ & $13.1 \pm 0.6^{a, b}$ & $19.5 \pm 0.66^{b}$ & $1.6 \pm 0.05^{\mathrm{d}, \mathrm{e}, \mathrm{f}}$ \\
\hline Nipomo $F_{1}$ & $13.5 \pm 4.0^{\mathrm{a}, \mathrm{b}}$ & $15.1 \pm 2.54^{a, b}$ & $1.2 \pm 0.02^{\mathrm{b}, \mathrm{c}, \mathrm{d}}$ \\
\hline Samba $F_{1}$ & $11.1 \pm 1.06^{a, b}$ & $16.8 \pm 1.46^{\mathrm{a}, \mathrm{b}}$ & $1.0 \pm 0,18^{b}$ \\
\hline Broker $F_{1}$ & $10.2 \pm 0.54^{a, b}$ & $15.7 \pm 1.03^{a, b}$ & $2.2 \pm 0.07 \mathrm{~g}, \mathrm{~h}, \mathrm{i}$ \\
\hline Rumba $F_{1}$ & $10.2 \pm 1.15^{\mathrm{a}, \mathrm{b}}$ & $16.2 \pm 1.80^{a, b}$ & $1.4 \pm 0.13^{b, c, d}$ \\
\hline Nerac $F_{1}$ & $9.8 \pm 0.27^{a, b}$ & $15.2 \pm 0.85^{a, b}$ & $1.4 \pm 0.03 \mathrm{~b}, \mathrm{c}, \mathrm{d}$ \\
\hline Napa $F_{1}$ & $7.2 \pm 0.85^{a, b}$ & $12.4 \pm 1.28^{\mathrm{a}, \mathrm{b}}$ & $1.4 \pm 0.066^{b, c, d}$ \\
\hline Bangor $F_{1}$ & $7.1 \pm 1.00^{a, b}$ & $11.4 \pm 3.72^{\mathrm{a}, \mathrm{b}}$ & $1.1 \pm 0.12^{\mathrm{b}, \mathrm{c}}$ \\
\hline Deep Purple $F_{1}$ & $0.9 \pm 0.34^{\mathrm{a}}$ & $1.3 \pm 0.53^{a}$ & $2.2 \pm 0.07 g, \mathrm{~h}, \mathrm{i}$ \\
\hline Yellowstone $F_{1}$ & $0.5 \pm 0.09^{a}$ & $0.5 \pm 0.13^{\mathrm{a}}$ & $2.2 \pm 0.02^{h, i}$ \\
\hline White Satin $F_{1}$ & $0.1 \pm 0.001^{\mathrm{a}}$ & $0.1 \pm 0.01^{\mathrm{a}}$ & $0.4 \pm 0.04^{a}$ \\
\hline
\end{tabular}

${ }^{*}$ f.w. - fresh weight. Date represents the mean \pm S.E.M. of four independent measurements. Values within column followed by the same letter are not significantly different at $P=0.05$ (Duncan's test). purple cultivar but with a yellow core. Other researchers have also investigated the carrots of different colors. Surles et al. (2004) showed that in the white roots the total of carotenoids content was $0.014 \mathrm{mg} / 100 \mathrm{~g}$ of fresh weigh, the yellow $0.71 \mathrm{mg} / 100 \mathrm{~g}$ of fresh weigh, while the purple had $17.5 \mathrm{mg}$. These results are significantly different from obtained by us. A similar relationship is visible when compared with data obtained by Sun et al. (2009). This probably results from the different methods of extraction and chromatographic separation. The results received from analysis of traditional orange carrots seems to be noteworthy. The content of total carotenoids in the cultivars with orange roots ranged from 12.29 to $48.6 \mathrm{mg} / 100 \mathrm{~g}$ of fresh weigh. These results are really difficult to confront. As mentioned earlier, most work on the total content of carotenoids in carrots, considers only the differences resulting from different color and regrettably there is lack of the cultivars characteristics. The literature data provide content from 9.1 to $40 \mathrm{mg} / 100 \mathrm{~g}$ fresh weight (Konings \& Roomans, 1997; Burns et al., 2003; Surles et al., 2004; Mayer-Miebach et al., 2005; Sun et al., 2009; Murillo et al., 2010). Orange cultivars which have been tested, contain concentration of carotenoids located in these range, with the exception of 'Korund $\mathrm{F}_{1}$ ', which showed a slightly higher carotenoids content (Table 1.).

The antioxidant capacity of extracts, measured by DPPH method, doesn't correspond with the carotenoids content. Method demonstrated that cultivars containing the highest level of carotenoids have average antioxidant capacity. 'Kazan $\mathrm{F}_{1}$ ' is an exception which shows positive correlation between carotenoids content and antioxidant capacity. The purple cultivar 'Deep Purple' revealed high antioxidant capacity despite the fact that it contain low level of carotenoids. Probably the antioxidant properties of hexane-ethanol extracts were caused not 
only by carotenoids but also by other compounds like tocopherols, unsaturated fatty acids and polyphenols like anthocyanidins ('Deep Purple'). Cultivars with low concentration of total carotenoids, like 'Deep Purple $F_{1}$ ' and 'Yellowstone $\mathrm{F}_{1}$ ' have demonstrated a higher proportion of xanthophylls in relation to $\beta$-carotene and other carotenoids (Table 1).

\section{Acknowledgements}

This work was supported by the Ministry of Science and Higher Education, grant no NN 312252536.

\section{REFERENCES}

Andersson SC, Olsson M E, Johansson E, Rumpunen K (2009) Carotenoids in Sea Buckhorn (Hippophae rhamnoides L.) berries during ripening and use of pheophityn a as a maturity market. J Agric Food Chem 57: 250-258.

Arscott SA, Tanumihardjo SA (2010) Carrots of many colors provide basic nutrition and bioavailable phytochemicals acting as a functional food. Compr Rev Food Sci F 9: 223-239.

Burns J, Fraser PD, Bramley PM (2003) Identification and quantification of carotenoids, tocopherols and chlorophylls in commonly consumed fruits and vegetables. Phytochemistry 62: 939-947.

El-Agamey A, Lowe GM, McGarvey DJ, Mortensen A, Phillip DM, Truscott TG, Young AJ (2004) Carotenoid radical chemistry and antioxidant/pro-antioxidant properties. Arch Biochem Biophysics 430: 37-48.

Główny Urząd Statystyczny (2009) www.stat.gov.pl/cps/rde/xbcr/gus/ PUBL_RL_wstepny_szacunek_ziem_roln_ogr_2009.pdf (in Polish).

Grassmann J, Schnitzler WJ, Habegger R (2007) Evaluation of different coloured carrot cultivars on antioxidative capacity based on their carotenoid and phenolic contents. Int J Food Sci and Nutr 58: 603-611.

Grune T, Lietz G, Palou A, Ross AC, Stahl W, Tang G, Thurnjam D, Yin Shi-an, Biesalski HK (2010) $\beta$-carotene is an important vitamin A source for humans. J Nutr 140,12S-I, Suppl.

Konings EJM., Roomans HHS (1997) Evaluation and validation of an LC method for the analysis of carotenoids in vegetables and fruit. Food Chem 59: 599-603.

Krinsky NI, Yeum KJ (2003) Carotenoid-radical interactions. Biochem Biophys Res Commun 305: 754-760.

Mayer-Miebach E, Behsnilian D, Regier M, Schuchmann HP (2005) Thermal processing of carrot: lycopene stability and isomerisation with regard to antioxidant potential. Food Res Int 38: 1103-1108.

Mozaffarieh M, Sacu S, Wedrich A (2003) The role of the carotenoids, lutein and zeaxanthin, in protecting against age-related macular degeneration: A review based on controversial evidence. Nutrit J 2: 20.

Murillo E, Melendez-Martinez AJ, Portugal F (2010) Screening of vegetables and fruits from Panama for rich sources of lutein and zeaxanthin. Food Chem 122: 167-172.

Paolini M, Abdel-Rahman SZ, Sapone A, Peduli GP, Perocco P, Cantelli-Forti G, Legator MS (2003) $\beta$-Carote: a cancer chemopreventive agent or co-carcinogen? Mutat Res 543: 195-200.

Rao LG, Rao LG (2007) Carotenoids and human health. Pharmacol Res 55: 207-216.

Stahl W, and Sies H (2003) Antioxidant activity of carotenoids. Mol Aspects Med 24: 345-351

Sun T, Simon PW, Tanumihardjo SA (2009) Antioxidant phytochemicals and antioxidant capacity of biofortied carrots (Daucus carota L.) of various colors. I Agric Food Chem 57: 4142-4147.

Surles RL, Weng N, Simon PW, Tanumihardjo SA (2004) Carotenoid profiles and consumer sensory evaluation of speciality carrots (Daucus carota, L.) of various colors. I Aori Food Chem 52: 3417-3421.

Wang CC, Chang SC, Inbaraj BS, Chen BH (2010) Isolation of carotenoids, flavonoids and polysaccharides from Lycium barbarum L. and evaluation of antioxidant activity. Food Chem 120: 184-192. 
